\title{
POWER COOLING AND MULPIC TECHNOLOGY FOR HOT ROLLED FLAT AND PLATE PRODUCTION*
}

Lukas Pichler ${ }^{1}$

Klaus Weinzierl ${ }^{2}$

Sandip Samanta ${ }^{3}$

\begin{abstract}
The market trend of advanced high strength steel (AHSS) with demand for higher strength products is increasing continuously. The inline cooling technologies have established as the most powerful metallurgical tool to achieve these demands. However, the cooling capabilities of existing hot strip mills, plate and Steckel mills are often not adequate to generate high cooling rates and the cooling accuracy required for the production of AHSS. Hence there have been many developments for an intensive, highly flexible accurate homogeneous cooling technology. Considering the wide variety of strip and plate geometry, Primetals Technologies have developed Power Cooling Technology for strip and introduced MULPIC ${ }^{\circledR 4}$ Technology for the plate production. In this paper we shall discuss these enhanced technologies that provide the inline cooling requirement with examples from the recently commissioned machines.
\end{abstract}

Keywords: Cooling competencies; Hot rolling; Plate and Steckel mil; Power cooling; MULPIC ${ }^{\circledR}$.

1 DI DR, Technology Hot and Cold Rolling, Primetals Technologies Austria GmbH, Linz, Upper Austria, Austria.

DR, Models Electrics \& Automation, Primetals Technologies Germany GmbH, Erlangen, Germany. Plate \& Aluminum, Primetals Technologies Ltd., Sheffield, Great Britain.

$M U L P I C^{\circledR}$ is a registered trademark of Centre de Recherches Metallurgiques ASBL (CRM). 


\section{INTRODUCTION}

Following market demands currently the general trend is to produce advanced steel grades either with higher strength or larger thickness at reduced costs compared to conventional production. This includes all kinds of AHSS such as DP (Dual-Phase), CP (Complex-Phase), TRIP (Transformation Induced Plasticity), fully-martensitic steels or HSLA grades (e.g. API X70, X80).

Especially when using lean chemistry approaches high cooling rates become important for virtually all advanced steel grades. In order to cover the emerging field of hot rolled multi-phase steels such as TRIP grades, accurate temperature-time path control is needed in a range where the Leidenfrost effect - an insulating steam layer between hot strip surface and cooling water is established - becomes dominant, i.e., fast and homogeneous cooling is of vital interest in the late cooling stage.

In order to account for above mentioned production strategies, one of the appropriate products on the market is the Primetals Power Cooling system. This system has recently been installed at HSM no. 2 of WISCO (Wuhan Iron \& Steel Company). The system is characterized by adjustable cooling rates ranging from moderate cooling rates up to the theoretical limit given by thickness and heat conductivity of the steel strip to be cooled. The Power Cooling system at Wuhan Iron and Steel Company's (WISCO) HSM No. 2 comprises 36 pairs of top and bottom headers with maximum achievable cooling rates three times higher than for conventional laminar cooling systems. The automation system of the Power Cooling consists of a comprehensive model. It computes in real time strip temperatures from roughing mill to the downcoiler as well as the booster pump speed. This way, pressure is controlled with high dynamics and allows rising pump speed and water pressure just in time, i. e. within switching time of valves. This results in a wide flexibility for the customer, since valves can be controlled down to $7 \%$ of maximum water.

MULPIC ${ }^{\circledR}$ has been developed for wide and thick plates and a standard machine would be $24 \mathrm{~m}$ long. However, existing plate mills have restricted layout and often the existing laminar cooling is retained for better asset utilization. In this paper we shall describe how the flexibility has been added in the standard MULPIC ${ }^{\circledR}$ to support existing cooling machine upgrade.

\section{PRODUCTION OF ADVANCED HOT-ROLLED STEEL GRADES}

The mechanical properties of hot rolled strips strongly depend on their chemistry and microstructure. The major factors of influence on strength, ductility and toughness of the material are mixed crystal strengthening, grain refinement, content of nonequilibrium phases as well as size and amount of precipitates.

In order to arrive at the desired properties of the final product careful choice of the time-temperature deformation path on the hot strip mill is a must. This includes proper thermomechanical treatment during deformation steps at the roughing and finishing stage as well as the proper cooling strategy at the ROT. Especially for lean chemistries the former usually provides challenges in view of throughput as the requirement of low rolling temperatures for properly pancaked microstructure before transformation and sufficiently high furnace exit temperatures necessary for dissolution of precipitations causes significant constraints for proper pass schedules. Figure 1 (left) shows schematically the different cooling courses for various types of steel grades produced including the influence of major alloying elements on the $\gamma->\alpha$ phase transformation kinetics. Virtually all important alloying elements delay the 
transformation from austenite to ferrite, pearlite and non-equilibrium phases. Besides accounting for base strength, to achieve desired amounts of e. g. bainite and martensite in the final product, proper alloying with delaying elements or high cooling rates have to be used. The potential for saving alloying elements by applying higher cooling rates can be estimated via known correlations [2] between cooling gradient, resulting grain size and influence of grain size on material strength. In addition, well calibrated material property simulation tools such as the Microstructure Monitor [3] are helpful, in particular if it comes to estimate the influence of alloying elements on material strength.

Material strengthening by exploiting the Hall-Petch effect, i. e., generation of fine ferrite grain is achieved by applying fast cooling at the early cooling stage. Typically, ferrite grain diameters found after accelerated cooling follow an inverse power law of the cooling rate applied, i. e., the higher the cooling rate the smaller the grain size and, hence, the stronger the matrix. Figure 1 (right) shows the impact of different time-temperature deformation paths on the microstructure of $X 70$ grades.

In order to arrive at the proper microstructure for dual phase (ferrite-martensite) or TRIP-steel (ferrite-(bainite)-residual austenite) one or more holding stages are necessary to generate the necessary amount of ferrite and to account for the proper isothermal-bainite transformation to stabilize the residual austenite in the case of TRIP steels as well as a final quench to the martensite region for dual phase steel. In combination with the finishing mill exit speed the transformation kinetics of the corresponding alloys determine the necessary length of the run-out table.
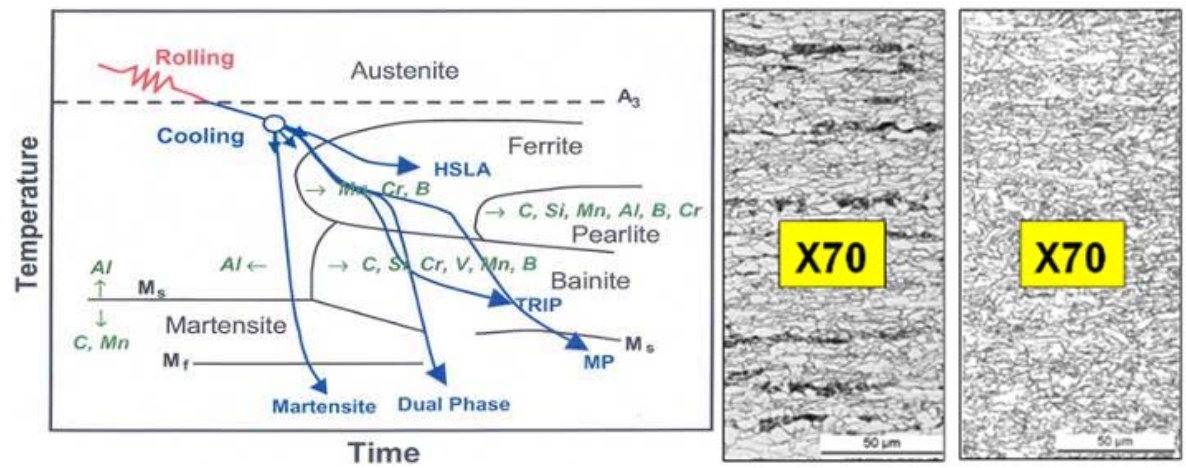

Figure 1. Left: Temperature-time paths for different types of hot-rolled steel grades including HSLA, martensitic steel, dual phase, TRIP and complex/multi-phase grades [5] Right: 1 microstructure of X70 after using different time-temperature-deformation strategies (left: finished rolling temperature (FRT) $\sim 700^{\circ} \mathrm{C}$, air cooling; right: FRT $\sim 850^{\circ} \mathrm{C}+$ accelerated cooling[4].

\section{PRIMETALS POWER COOLING - OVERVIEW}

Due to its extraordinarily high cooling capacity Power Cooling provides the means to sharply control the microstructural evolution within very short lengths. Depending on the detailed requirements given by product mix and layout of a rolling mill several locations for an installation of Power Cooling are identified [1]:

- $\quad$ TBC - Transfer bar cooling

- ISC - Interstand cooling

- EC - "Early cooling" (Pipe grades, HSLA steels, 2 step cooling - AHSS qualities)

- LC - "Late cooling" (2 step cooling, AHSS steel grades - e.g. hot rolled DP, TRIP, Multi-phase steel grades) 


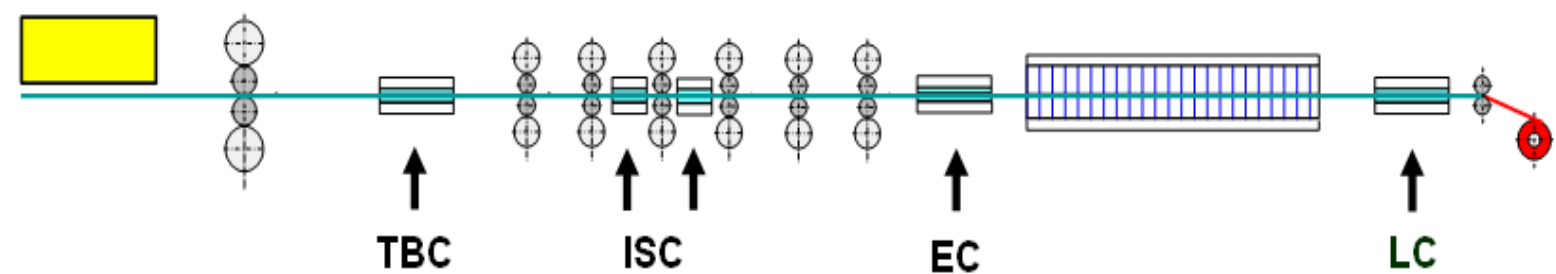

Figure 2. Layout of a hot strip mill with possible applications of the Power Cooling Technology.

The Transfer Bar Cooling and Interstand Cooling location addresses throughput topics in view of thermomechanical rolling whereas the EC and LC location addresses the austenite-ferrite and the austenite-bainite/martensite transformation on the ROT with smallest possible wet zone length. In addition, using Power Cooling in the LC section provides the possibility to stably operate the cooling near the Leidenfrost region which is of increasing importance in view of DP and TRIP steels. Especially late cooling becomes more and more important for producing new steel grades, particularly multi-phase steel, which requires an interrupted cooling strategy combined with sufficiently high cooling rates during the final cooling stage.

Rapid cooling of the material ensures better and more uniform metallurgical properties and thus increases the quality of the hot rolled strip.

Compared to laminar/intensive laminar cooling installations Power Cooling shows significantly higher water flows resulting in heat fluxes up to $5 \mathrm{MW} / \mathrm{m}^{2}$ and cooling rates close to the theoretical limit given by strip dimension, heat capacity and heat conductivity of the steel (see Table 1), while maintaining a wide control range for applicable flow rates to account for maximum metallurgical flexibility.

Table 1. Comparison of flow adjustment range and cooling rates reachable for different cooling technologies

\begin{tabular}{|l|c|c|c|}
\cline { 2 - 4 } \multicolumn{1}{c|}{} & $\begin{array}{c}\text { Laminar } \\
\text { Cooling }\end{array}$ & $\begin{array}{c}\text { Turbo - Laminar } \\
\text { Cooling }\end{array}$ & $\begin{array}{c}\text { Power } \\
\text { Cooling }\end{array}$ \\
\hline Adjustment range & $25-100 \%$ & $25-100 \%$ & $7-100 \%$ \\
\hline $\begin{array}{l}\text { Cooling rate Structural steel } \\
\text { h=6mm }\end{array}$ & $\sim 45^{\circ} \mathrm{C} / \mathrm{s}$ & $\sim 64^{\circ} \mathrm{C} / \mathrm{s}$ & $\sim 175^{\circ} \mathrm{C} / \mathrm{s}$ \\
\hline $\begin{array}{l}\text { Cooling rate Structural steel } \\
\text { h=12.2mm }\end{array}$ & $\sim 24^{\circ} \mathrm{C} / \mathrm{s}$ & $\sim 34^{\circ} \mathrm{C} / \mathrm{s}$ & $\sim 85^{\circ} \mathrm{C} / \mathrm{s}$ \\
\hline $\begin{array}{l}\text { Cooling rate Structural steel } \\
\text { h=25.4mm }\end{array}$ & $\sim 11.5^{\circ} \mathrm{C} / \mathrm{s}$ & $\sim 17^{\circ} \mathrm{C} / \mathrm{s}$ & $\sim 40^{\circ} \mathrm{C} / \mathrm{s}$ \\
\hline
\end{tabular}

For existing installations Power Cooling technology gives the opportunity to significantly extend the product mix towards high strength grades and endorses the development of existing steel grades based on leaner chemistries significantly contributing to higher profit margins.

\section{POWER COOLING INSTALLATION AT WISCO}

With the installation of Primetals Power Cooling immediately after the finishing mill of HSM No. 2 in Wuhan, the Chinese steel producer WISCO entered successfully the AHSS market. The equipment was preassembled on site into units that could be lifted into position by the overhead crane after the existing equipment had been removed. So, it was possible to minimize the total shutdown time to 15 days. To 
ensure proper drainage of the water on the top side, the roller table in the Power Cooling section was also exchanged.

Technical description of the equipment: The Power Cooling unit after the finishing mill consists of 36 top and 36 bottom headers with a maximum total water flow of about $16,200 \mathrm{~m}^{3} / \mathrm{h}$ at 3.5 bar water pressure. Each top header corresponds to one bottom header. The Power Cooling headers are equipped with solid jet nozzles to ensure maximum possible impact pressure.

The following table shows the key figures of the Power Cooling System:

Table 2. Key Figures of WISCO Power Cooling

\begin{tabular}{|l|c|c|}
\hline No. of top and bottom headers & 36 & \multirow{2}{*}{ "Booster" operation } \\
\hline Max water flow rate at 3.5 bar & $16,200 \mathrm{~m}^{3} / \mathrm{h}$ & \\
\hline Pressure at nozzle & $\max .3 .5 \mathrm{bar}$ & \multirow{2}{*}{ "Laminar" } \\
Water flow rate & $\sim 7,700 \mathrm{~m}^{3} / \mathrm{h}$ & operation \\
\cline { 1 - 2 } Pressure at nozzle & $\begin{array}{c}\text { max. } 0.8 \mathrm{bar}(\mathrm{supply} \\
\text { overhead tank) }\end{array}$ & \\
\hline Total length & $\sim 17 \mathrm{~m}$ & \\
\hline
\end{tabular}

Each pair of two top or two bottom Power Cooling headers features the following additional equipment:

- a pneumatically actuated on/off valve

- an electro - pneumatic flow control valve

- a manually operated valve

- a pressure transducer

For ventilation every top header is equipped with an automatic air venting valve. To calibrate each flow control valve, a flow measurement is integrated in a by-pass piping system. As mentioned above two headers are controlled by one pneumatic flow-control valve, which enables a wide control range of the flow rate. Because of the special design of the equipment, it is possible to reduce the flow rate for the Power Cooling headers to as low as $7 \%$ of the nominal flow.

The cooling section modernization included the installation of a new overhead tank. When extremely high cooling rates are required for some of the most critical products, it might happen that the overall flow rate required for cooling temporarily exceeds the supply to the tank. Since the tank is used as a buffer in this case, the total flow rate of the cooling water from the well to the tank could remain unchanged.

As for measurement a water free strip surface is needed, specially designed cross sprays are arranged between the gauge house and the first cooling header of the cooling section. Additional air sprays are installed at the same position to blow off the rest of the water and dry the surface.

\section{ENERGY SAVINGS DUE TO LAMINAR MODE AND POWER COOLING MODE}

To produce high-strength steel grades (AHSS), e. g. HSLA steel or as-hot-rolled multi-phase steel high cooling rates are necessary, so frequency-controlled pumps supply the headers with water. Conventional steel grades do not require such high cooling rates. In that case Power Cooling can be operated in laminar mode, which means the water is gravity-fed from the new overhead tank. These two modes can be realized by switching a valve in the supply line from the tank. 


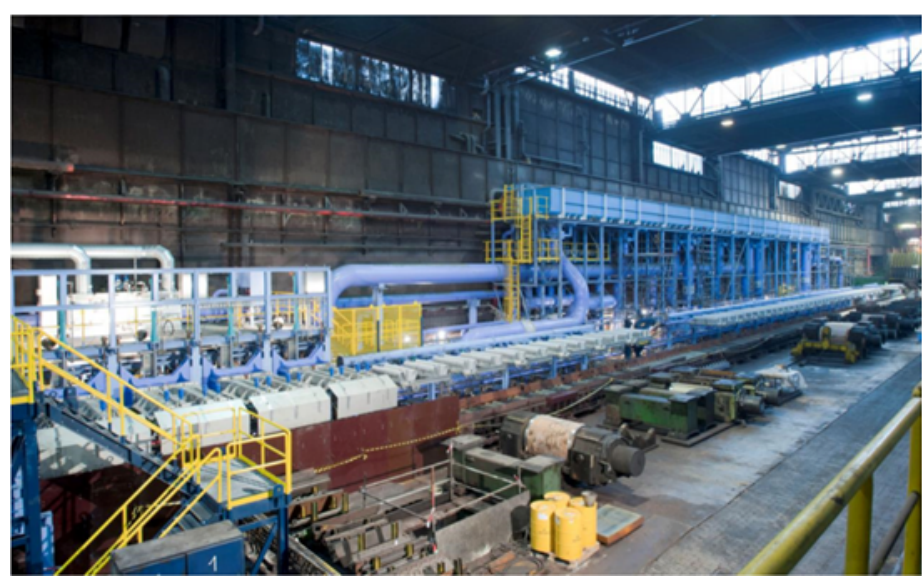

Figure 3. Newly installed overhead tank.

If switched to pressure mode, for each strip the desired pressure is derived from the cooling rate needed just a few seconds before the strip enters the cooling line. This is possible, because pumps are frequency controlled. Hence, pressure mode can be applied to conventional grades as well. In case that only some lower cooling rate is needed, desired pressure simply reduces down to minimum pressure (1.6bar) to save electrical energy. Doing this, product with high cooling rates can be mixed arbitrarily into normal production and no gap between strips is needed for switching of operating mode anymore. Thus, energy consumption for booster pumps is minimized in pressure mode as well and would read typically negligible $60 \mathrm{~kW}$ then for conventional production and may rise to some higher value up to $1.4 \mathrm{MW}$ only if full amount of water at max. cooling rate is needed.

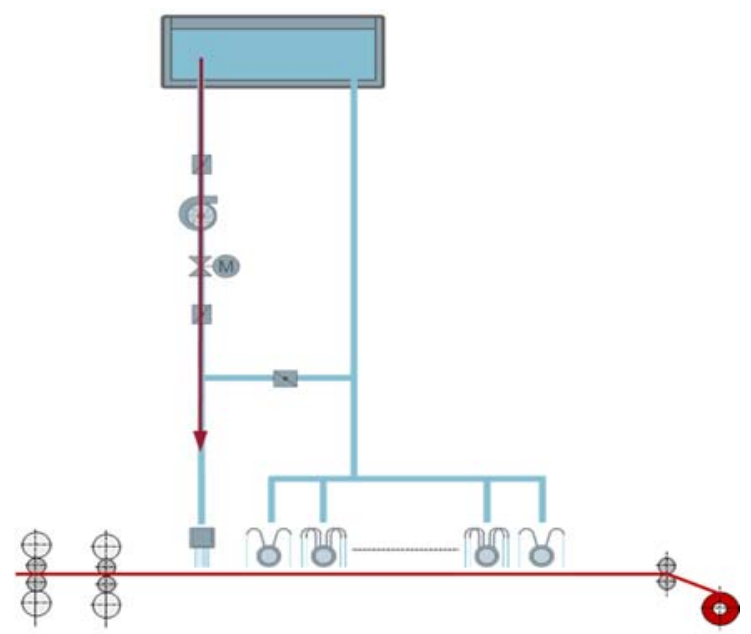

Figure 4. Switching of modes.

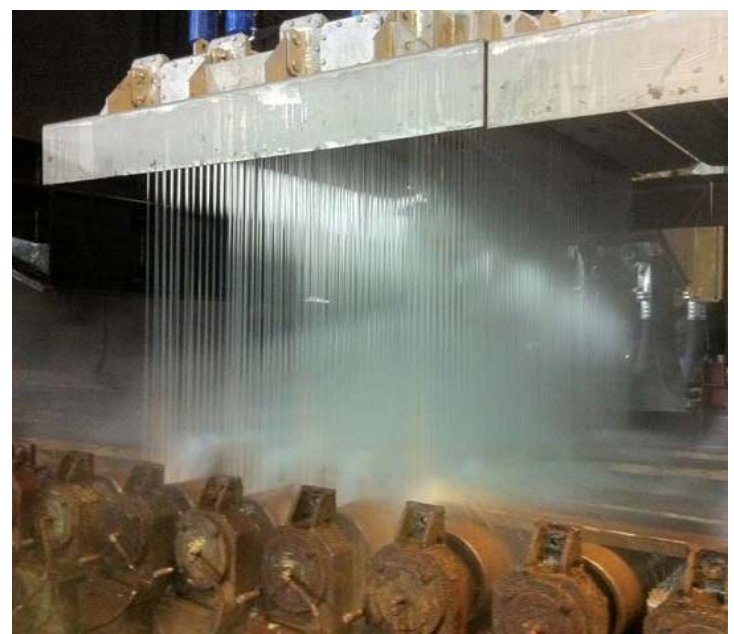

Figure 5. Power Cooling headers in operation.

\section{COMPREHENSIVE TEMPERATURE MODEL WITH POWER COOLING}

For improving the accuracy of temperature control a completely new automation strategy was developed. This new process automation allows excellent performance figures for coiling temperatures, although the increase of the water flow by the supplying water management system is up to 10 times faster than for hot strip mills with standard laminar cooling only. This means that there is especially no loss of coiling temperature performance for products in case that Power Cooling device is used (up to full power/cooling rate) instead of laminar cooling before. 
At WISCO, the new L2 cooling process automation system has been integrated into the existing system, and a new L2 process computer together with a Simatic basic automation has been delivered. Before shutdown, the new L2 model has been configured with the existing laminar cooling mechanics and has been tested in listening mode. During the shutdown period, the configuration has been changed to the new mechanical layout. New sensors have been installed and connected. Two days before startup, valve characteristics and characteristic curves of pumps have been measured, and valve flow has been calibrated.

At day of startup, the production started with conventional laminar product. The Power Cooling unit was switched to laminar mode, and cooling rate for Power Cooling unit was desired in a way that the cooling rate was same as before, i. e. same as old laminar valves which have been removed. This way, the entire production could be taken without visible changes on material properties. Performance and amount of produced strips of the first days of production with the new system have been similar to the period before.

Two weeks after startup, the Power Cooling unit was switched to pressure mode for the first time, and the first strips have been produced with high cooling rates.

Today, WISCO is using pressure mode for their entire production with great success. All strips previously cooled in laminar mode now are cooled with booster pumps in quasi-Laminar mode, i. e. in pressure mode with lowest possible desired pressure. Laminar mode isn't used anymore. Higher cooling rates can be easily desired for all strips needed just by selecting the appropriate primary data. This way, they do not need to think about special product schedules grouping strips with high cooling power together to reduce the number of production gaps for switching (40s are required for changing from laminar mode to power mode and vice versa) anymore. Handling is as easy as for the Laminar cooling device before. Figure 6 shows the structure of the process automation system.

Every $200 \mathrm{~ms}$, the process computer receives measured data from the roughing mill, the finishing mill, the cooling section and the water supply system. Strips are set up at the roughing mill stand and are tracked by the model from the roughing mill throughout the finishing mill and the cooling section in real time until they are coiled. Thus, the horizon of the comprehensive model covers the area in front of the finishing mill, the finishing mill itself and the cooling section. Since the model describes the entire finishing mill, computed finishing mill exit temperatures are available, and the Power Cooling unit can be activated exactly when needed at the right time before the strip head enters the cooling section. All predictions made by the model can start while the strip has not yet entered the cooling section. This way, the cooling model has knowledge about actual strip temperatures and phase fractions and is capable to compute future strip temperatures when needed as soon as a strip enters the roughing mill stand. 


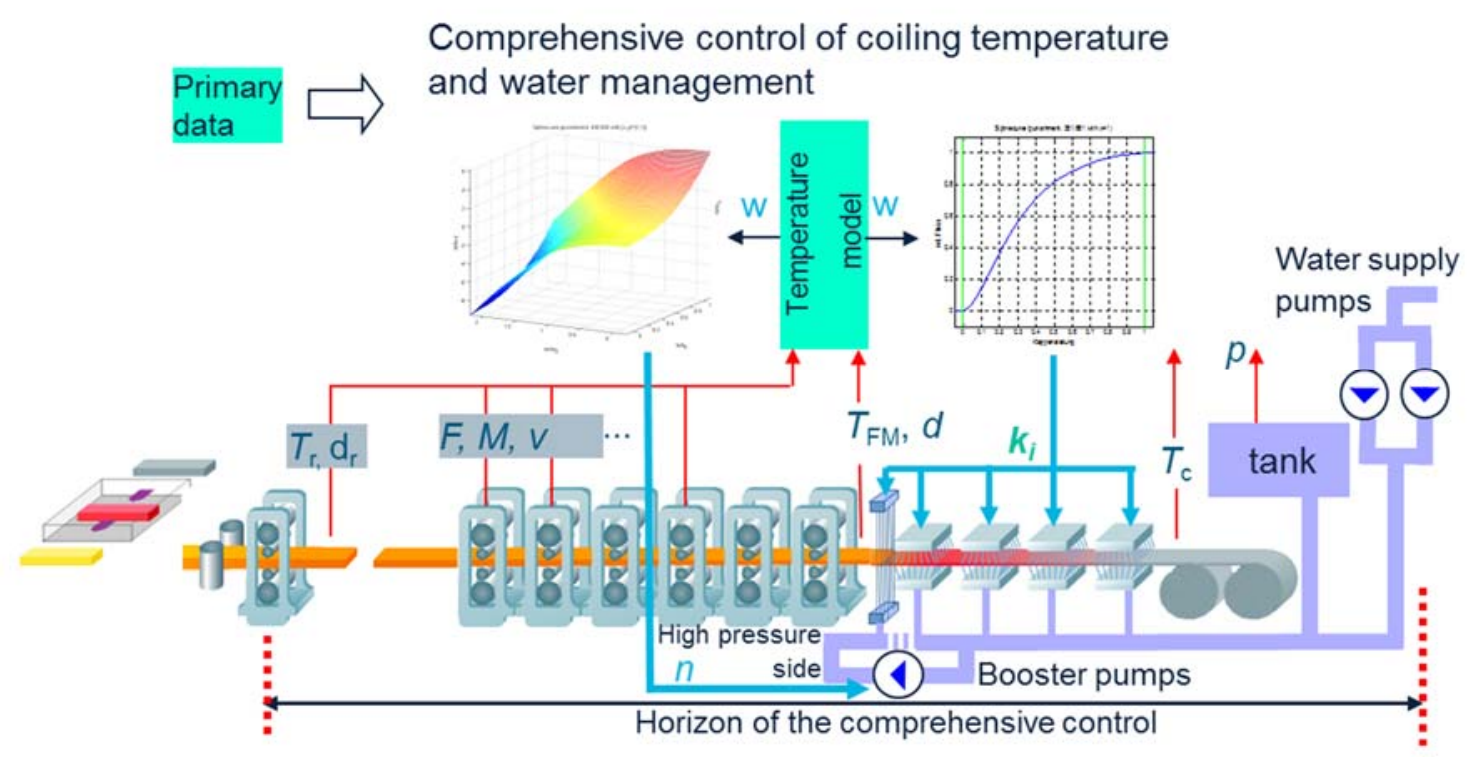

Figure 6. Structure of cooling control.

Moreover, the cooling model contains exact knowledge of the valve characteristics of all participating valves and the characteristics of the booster pumps as well. Hence, not only the temperature, but also pump speed and water pressure are controlled precisely in real time. Figure 7 and Figure 8 show results from controlling of booster pumps.

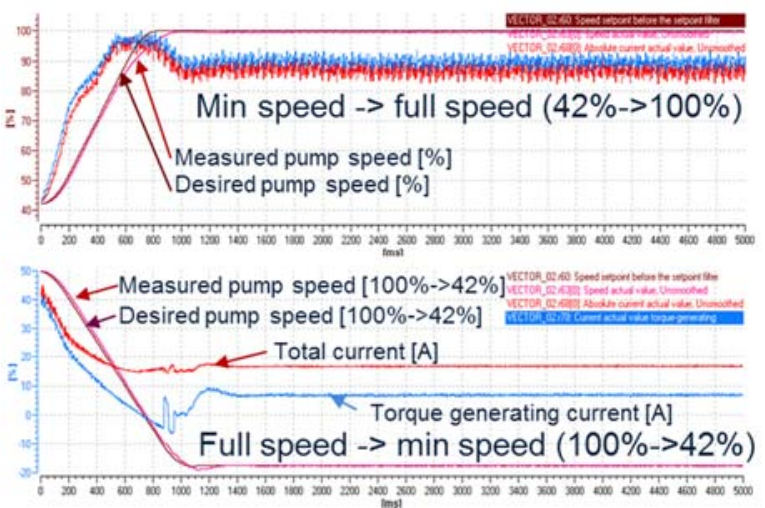

Figure 7. Converter step response results

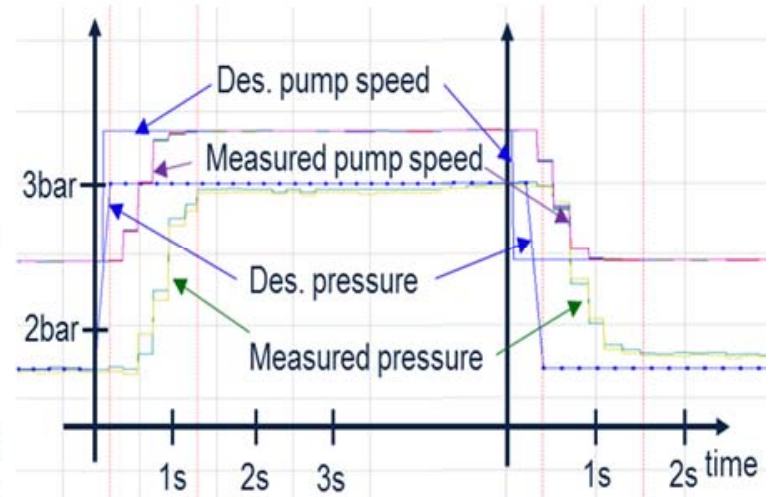

Figure 8. Step response of pressure control

Figure 7 shows the step response on desired pump speed, recorded using STARTER on the SINAMICS converter. Vector control has been applied to control the speed of the asynchronous pump motors to ensure high dynamics and accuracy of speed control. The pumps follow a ramp with a delay of less than $0.1 \mathrm{~s}$ and rise from minimum speed to full speed within 1s. Similar holds for a step from full speed towards minimum speed.

Figure 8 shows pressure control results of the entire process automation system. All 36 Power Cooling valves are fully opened in this example. The step response for desired pressure from min pressure of 1.6bar to almost max. pressure, 3bar, is shown. It can be seen that the entire pressure control is as fast as valves of a laminar cooling section can open; measured pressure settles at target value within less than $1.2 \mathrm{~s}$.

The idea of comprehensive process control now is as follows: The process model every $200 \mathrm{~ms}$ predicts future temporal trajectories for enthalpies, temperatures and 
phase fractions for respective strip points of the passing material. Details are described in [6]. Since the model, furthermore, knows all the relationships between water switched, resulting temperatures, angle of valve actuators, pump speed, water flowing through pumps at given speed etc. as well as plant limitations like minimum pump speed, minimum and maximum water flow of pumps, the model can desire actual pump motor speed and valve actuator settings in a comprehensive manner within a single setpoint telegram. Hence, temperature, water flow and water pressure are controlled simultaneously with excellent performance and speed and consistency of pump speed to water switched is always ensured. Thus, there is no loss of speed and performance even if strips are cooled that enter the Power Cooling with $10 \mathrm{~m} / \mathrm{s}$ strip speed and need to be cooled with full power. This means that amount of water needs to rise from 0 to $16,000 \mathrm{~m}^{3} / \mathrm{h}$ within $1.7 \mathrm{~s}$ to follow the first strip point of the body immediately behind some uncooled head while it is passing the $17 \mathrm{~m}$ long Power Cooling unit with $10 \mathrm{~m} / \mathrm{s}$.

As a final result, production of an $18 \mathrm{~mm}$ strip X100 is demonstrated.

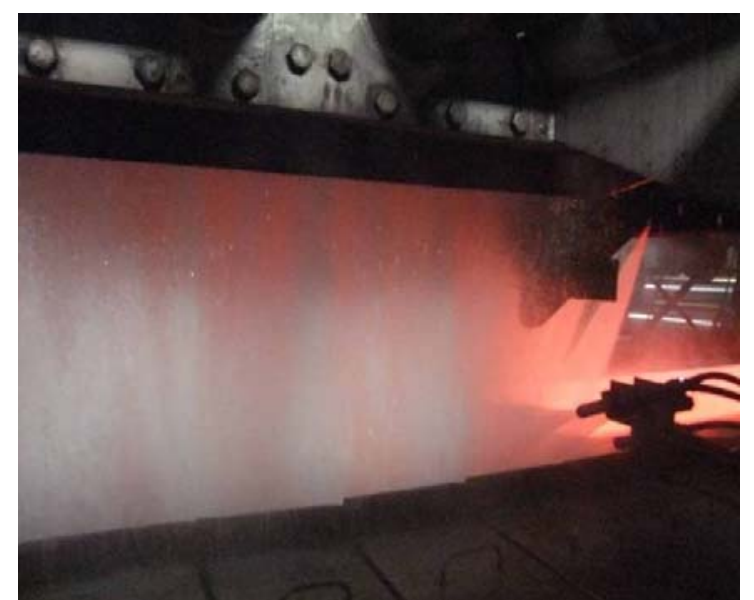

Figure 9. Power Cooling machine with cross sprays in operation.

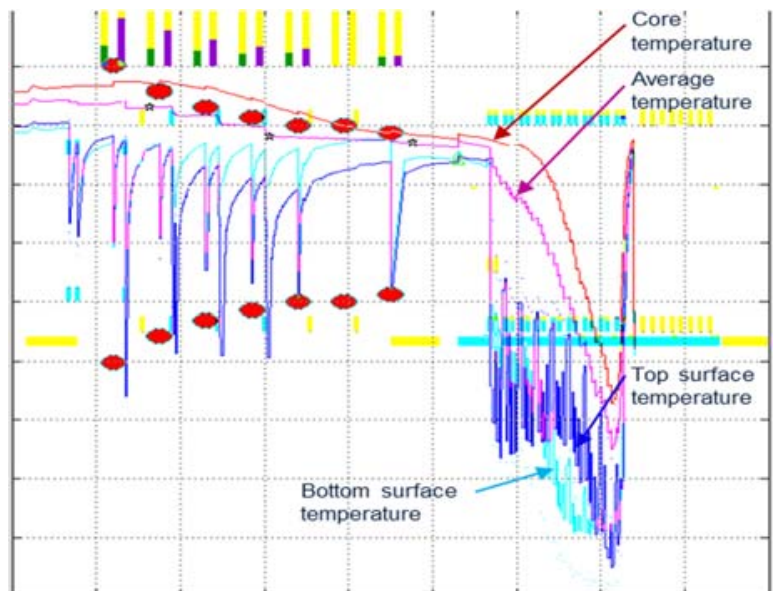

Figure 10. Computed temperatures of X100

The target value for the coiling temperature was $350^{\circ} \mathrm{C}$, cooling rate and amount of water was almost full power of the Power Cooling machine. A snapshot of the strip leaving the Power Cooling machine is shown in Figure 9. The computed strip temperatures at this time are depicted in Figure 10.

\section{PLATE COOLING TECHNOLOGY MULPIC ${ }^{\circledR}$}

The In-line intensive cooling process has become a standard metallurgical tool in modern plate mills in order to produce higher strength and value add grades. This requires higher cooling rates and better cooling accuracy along the length and width of the plate. Since 2002, Primetals Technologies has commissioned many MULPIC ${ }^{\circledR}$ (Multi Purpose Interrupted Cooling) machines at plate mills around the world.

The MULPIC ${ }^{\circledR}$ first conceived by CRM and now jointly developed with Primetals Technologies, consists of 48 headers grouped into 24 opposing pairs, see Figure 11. Each header is one meter in length and will be slightly wider than the mill run-out table. In a standard machine, top headers are grouped into four banks, banks $A, B, C$ and $D$, with six header pairs per bank. The top headers of each bank are mounted in a frame that is supported at each corner on a jacking system. When rolling non- 
cooled plates the top banks are raised at $1000 \mathrm{~mm}$ above the run-out table. The headers are lowered to as little as $500 \mathrm{~mm}$ above the plates during cooling.

Until recently, majority of these installations were standard MULPIC ${ }^{\circledR}$ machines of $24 \mathrm{~m}$ in length. However, recently, existing plate producers are looking for performance improvements by adding high flow density headers in front of existing laminar cooling sections. This hybrid configuration as shown in Figure 12 provides several challenges for process control as well as engineering. Several steps have been taken to ensure a smooth and rapid design, installation, start-up and fast achievement of the results.

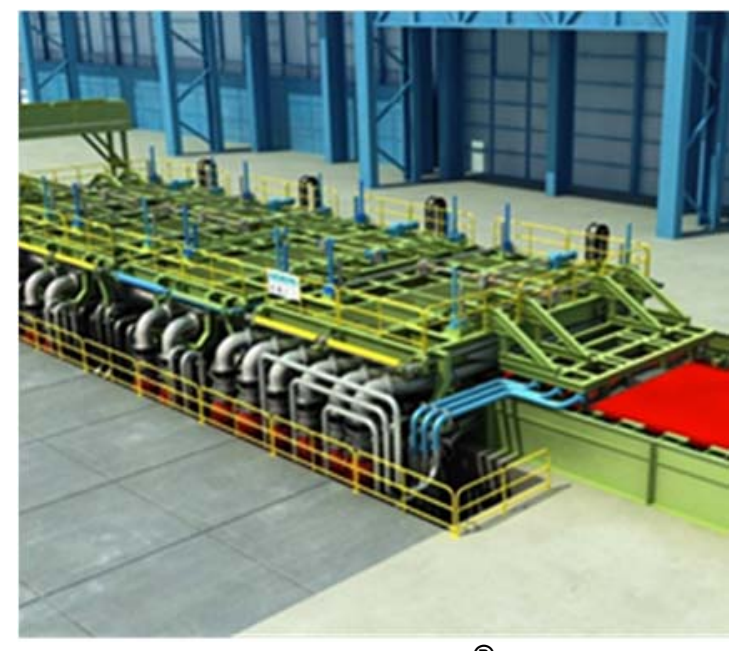

Figure 11. Standard MULPIC ${ }^{\circledR}$.

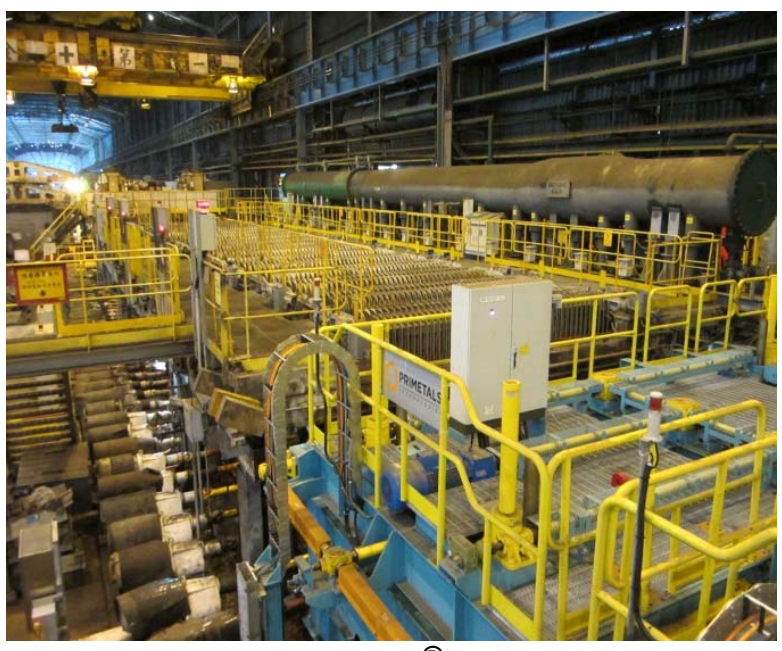

Figure 12. Hybrid MULPIC ${ }^{\circledR}$.

Many customized design features like flexible hose, new flow control valve and hybrid cooling model have been introduced to improve performance and ease integrating MULPIC $^{\circledR}$ in to existing systems. The major challenge in modernizing existing Plate mills is the restriction of space. The MULPIC ${ }^{\circledR}$ piping arrangement has been modified such that the machine and peripheral devices can be fit in the space available in the existing line.

While for a green field project a large pit area is designed for the water piping, for retrofitting in existing line, flexible hose has been used in several projects. In certain circumstances where horizontal space is not available, it may be possible to reorient the pipework and run it vertically as in Figure 13. In these cases, we must take care to avoid cranes, walkways and other services which may be present.

During one recent project where it wasn't possible to excavate a pit deep enough to install the standard telescopic pipework, we developed a new pipework arrangement utilizing large double braided stainless steel hoses (Figure 14). These allowed the MULPIC ${ }^{\circledR}$ to retain the height adjustable top headers, and the maintenance access they provide, while working within the constraints of the available space. This saved us and the client significant time, money and complexity making the project viable.

Another important aspect of hybrid machine is to integrate process model and control logic for all 3 modes of operations, i.e., MULPIC ${ }^{\circledR}$ only, Laminar only and MULPIC $^{\circledR}+$ Laminar. Primetals Technologies have implemented and successfully commissioned these process models in several plate mills. 


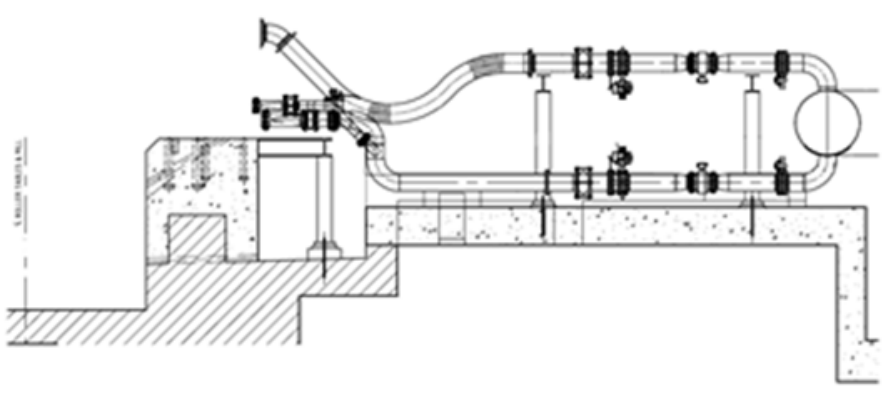

Figure 13. Tall and shallow pipe

Figure 14. Wide and low pipe arrangement. arrangement.

\section{CONCLUSION}

The cooling capabilities of existing hot strip mills, plate and Steckel mills are often not sufficient to achieve high cooling rates and thus the cooling capacity is often not sufficient for the production of AHSS, pipe grades and DP. In this paper, the portfolio of Primetals Technologies for intensive, highly flexible, accurate, homogeneous cooling technology is discussed.

The installation of the Power Cooling equipment allows adjustment of high cooling rates and therefore superior microstructure. A Power Cooling system in front of the downcoiler allows achieving the required holding time for multiphase-steels, especially when the cooling section is not long enough. Also the cooling performance in the unstable film boiling regime increases significantly.

MULPIC ${ }^{\circledR}$ has been established as the market leader in plate cooling technologies and Primetals is continuously developing the performance of the machine and align with the ever changing requirement of the plate producers.

\section{REFERENCES}

1 J. Maierl, J. Thoresson, E. Opitz, K. Weinzierl: High performance solutions for rolling of advanced high-strength steel grades in hot-strip mills. METEC 2015, 16.June - 20. June 2015

2 G. Zouhar: Darstellung und Bewertung des Erkenntnisstandes zur quantitativen Beschreibung der Gefügeentwicklung beim Warmwalzen unlegierter Stähle und zur Berechnung mechanischer Eigenschaften. Internal research report of TU Dresden, 1996.

3 H.U. Löffler, " Microstructure Modeling using Artificial Neural Networks". In: Continuum Scale Simulation of Engineering Materials, Fundamentals - Microstructures - Process Applications. Raabe, D., Roters, F., Barlat, F., Chen, L.-Q. (Eds.), Wiley 2004. ISBN 3527-30760-5, pp. 829-843.

4 source: voestalpine Grobblech $\mathrm{GmbH}$

5 source: voestalpine Stahl $\mathrm{GmbH}$

$6 \quad$ K. Weinzierl, H. U. Löffler, M. Rößiger and U. Houben: Comprehensive Strip Temperature and Microstructure Control revolutionizes Hot Strip Mill Automation. AISTECH-Conference proc. 2, pp. 1051-1060, Warrendale, Pa. 2011 